\title{
Are persons with fibromyalgia or other musculoskeletal pain more likely to report hearing loss? A HUNT study
}

\author{
Magne Stranden ${ }^{1,4^{*}+} \mathbb{D}$, Håvard Solvin ${ }^{1 \dagger}$, Egil A. Fors ${ }^{1}$, Linn Getz ${ }^{1}$ and Anne-S. Helvik ${ }^{1,2,3}$
}

\begin{abstract}
Background: Leading theories about the pathogenesis of fibromyalgia focus on central nervous dysregulation or sensitization, which can cause altered perception. There is growing evidence that fibromyalgia involves altered perception not only of pain, but also other sensory stimuli. On this basis, we investigated whether individuals with fibromyalgia are more likely to report subjective loss of hearing, adjusted for audiometrically measured loss of hearing, compared to persons without any musculoskeletal pain disorders. In addition, we studied persons with other musculoskeletal pain than fibromyalgia and persons who did not have any musculoskeletal pain.

Methods: The study includes 44494 persons from the second health survey in Nord-Trøndelag (HUNT2) who had undergone audiometry and answered a comprehensive questionnaire that mapped fibromyalgia, musculoskeletal pain at various sites and subjective hearing loss. Respondents with other musculoskeletal pain problems than fibromyalgia were divided into two groups with respectively localized and widespread musculoskeletal pain. Data were analyzed with logistic regression models adjusting for age, education, anxiety, depression and hearing thresholds.
\end{abstract}

Results: In adjusted analysis, individuals with fibromyalgia had increased likelihood to report subjective hearing loss, compared to persons without fibromyalgia or other musculoskeletal pain (OR 4.578, 95\% Cl 3.622-5.787 and OR 4.523, 95\% Cl 3.077-6.647 in women and men). Furthermore, people with local and widespread musculoskeletal pain not diagnosed with fibromyalgia, also had increased likelihood to report subjective hearing loss, compared to people with no musculoskeletal pain. This relationship was greater for widespread pain than for localized pain (OR 1. 915, 95\% Cl 1.627-2.255, and 1.796, 95\% Cl 1.590-2.029, in women and men with local musculoskeletal pain and OR 3. 073, 95\% Cl 2.668-3.539, OR 3.618, 95\% Cl 3.225-4.058, in women and men with widespread pain, respectively).

Conclusions: Our findings are consistent with the hypothesis that fibromyalgia is related to a general dysregulation of the central nervous system. The same might also be the case for other local and, in particular, other widespread, musculoskeletal pain.

Keywords: Fibromyalgia, Subjective hearing loss, Musculoskeletal pain, Central sensitivity syndrome, Chronic activation theory of stress, Allostatic load

\footnotetext{
* Correspondence: magst@stud.ntnu.no

${ }^{\dagger}$ Equal contributors

${ }^{1}$ Department of Public Health and General Practice, Faculty of Medicine,

Norwegian University of Science and Technology (NTNU), Trondheim,

Norway

${ }^{4}$ Harald Haarfagres gate 2, Trondheim NO-7041, Norway

Full list of author information is available at the end of the article
} 


\section{Background}

Prolonged pain from the musculoskeletal system and other symptoms currently associated with the diagnosis fibromyalgia have been described since ancient times [1, 2]. In the 1500s such symptoms was termed "rheumatism" [3] and in the 1700s "muscular rheumatism" [3]. From the early 1900s the term "psychogenic rheumatism" was presented, although it was assumed to be caused by muscular inflammation and preferentially named "fibrositis" [4-6]. Eventually, in 1976, the term fibromyalgia was coined [7], as the symptoms were no longer considered to have an inflammatory cause, i.e. the past prevailing paradigm since Gowers in $1904[3,8]$. The etiology and pathogenesis is since then often characterized as medically unexplained [9]. However, fibromyalgia may be considered as a "discrete diagnosis or as a constellation of symptoms characterized by central nervous system pain amplification with concomitant fatigue, memory problems, and sleep and mood disturbances"[10]. The estimated prevalence of fibromyalgia in the general population varies globally between approximately 2 and 11\%, depending on the population and study design [10,11]. The prevalence is higher in women than men (9:1), and increasing with age [12]. The diagnosis has until recently been determined by clinical examination according to the ACR 1990 criteria, in which the patient must have pain in all of the body's four quadrants plus axial pain, and at least $11 / 18$ predefined tender points, triggered by a pressure of a maximum of $4 \mathrm{~kg} / \mathrm{cm}^{2}$ [13]. In addition to being a chronic, widespread musculoskeletal pain condition without a well-defined cause, fibromyalgia is often accompanied by non-specific symptoms and comorbidities [14-16]. These include symptoms such as fatigue, memory and concentration problems [17], sleep disturbances, stomach ache, depressive symptoms and headache $[10,18,19]$, and disorders like irritable bowel syndrome (IBS), chronic fatigue syndrome (CFS/ME), interstitial cystitis (IC) and temporomandibular disorder (TMD) [8].

Due to the high prevalence of symptoms and comorbidities associated with fibromyalgia, researchers in various milieus have started to view fibromyalgia and related conditions as potentially explained by the same mechanisms [20]. The prevailing view is that they represent a similar, altered central neural processing of perceptive stimuli, rather than organspecific pathology. One suggested term to cover such a neural dysregulation condition is "centralized sensitization syndrome" (CSS) [21, 22]. Other research groups have launched concepts and theories, which are theoretically in good coherence with the notion of central sensitization. These include sustained arousal
[23], the Cognitive Activation Theory of Stress (CATS) [24] and allostatic overload [25]. Currently, these concepts exist more or less in parallel, and no consensus exists about the mechanisms [26, 27]. However, the diagnostic criteria for fibromyalgia have since 2010 been adapted to accommodate the frequent occurrence of associated symptoms and comorbidities [18]. The diagnosis can now be established by therapist interviews and self-reports by summing the pain localizations (0-19) in a "widespread pain index" (WPI) plus adding a 0-12 ranged "symptom severity" score (SSS) considering the comorbid symptoms mentioned above. This completes the ACR 2010 fibromyalgia criteria and the later 2011 "Fibromyalgia survey criteria" by a sum score of maximum 31 points where the fibromyalgia diagnosis is defined by a 12 point cut-off score [18, 19].

Recently, researchers have taken interest in how patients with fibromyalgia experience hearing. One study has found increased incidence of reported subjective hearing loss among persons with fibromyalgia, compared to individuals with inflammatory rheumatic disorders [28]. Fibromyalgia has also been associated with hypersensitivity to noise [29]. These findings are interesting in light of the theories concerning central sensitization, and are compatible with studies of cognitive dysfunction and memory problems in fibromyalgia and chronic widespread pain [17]. Another study has found poor correlations between subjective and objective hearing loss in patients with three or more medical unexplained symptoms, but that study did not include fibromyalgia per se [30]. It is thereby still unclear whether persons with fibromyalgia are more likely to report hearing loss than others. According to the theory of sustained arousal, one might hypothesize that if persons with fibromyalgia can be shown to experience auditory disturbances in addition to the previously documented problems with cognitive function and memory [17], similar auditory disturbances might also be found in persons with widespread muscular pain.

Based on The Nord-Trøndelag Health Study part 2 (HUNT2) and Nord-Trøndelag Hearing Loss study (NTHLS), the aim of the present study was to explore if people who report fibromyalgia or other musculoskeletal pain are more likely to have subjective hearing loss, compared to controls without such problems. More specifically, our research question is:

Are persons with fibromyalgia or other musculoskeletal pain, widespread or localized, more likely to report subjective hearing loss than persons without fibromyalgia or other pain, when adjusting for measured hearing thresholds, age, gender and education, as well as depression and anxiety? 


\section{Method}

\section{Study design and participants}

Data from HUNT 2 (1995-7) and the NTHLS were used in a retrospective cross-sectional study. HUNT2 and NTHLS are questionnaire-based, but hearing loss was assessed by audiologists who used mobile research units to measure audiometry.

In total, 66140 adults, age ranging from 20 to 101 years participated in HUNT2. Median age was 48, and mean age 50.2 years [31]. Hearing tests were available for 50465 participants. Persons with missing data on fibromyalgia, musculoskeletal pain and subjective hearing loss were excluded from the present study (Fig. 1). All participants in HUNT 2 and NTHLS provided informed, written consent to participate in research studies.

\section{Measures}

\section{Fibromyalgia}

Fibromyalgia was assessed with the question: "Has a physician ever said that you have had fibromyalgia (fibrositis/chronic pain syndrome)?" (HUNT 2 Q1) [32], with response alternatives "yes" or "no". An affirmative answer to this question classified respondents as having fibromyalgia. It is not known to what extent physicians used the tender-point criteria when establishing the diagnosis [13].

\section{Other musculoskeletal pain}

Other musculoskeletal symptoms than fibromyalgia were evaluated by self-report questions from the HUNT2 Q1 questionnaire [32]. Similar questions have shown good sensitivity and reproducibility in earlier studies [33-35]. The initial question was: "Have you during the past year suffered from pain and/or stiffness in muscles and limbs that have lasted for at least three

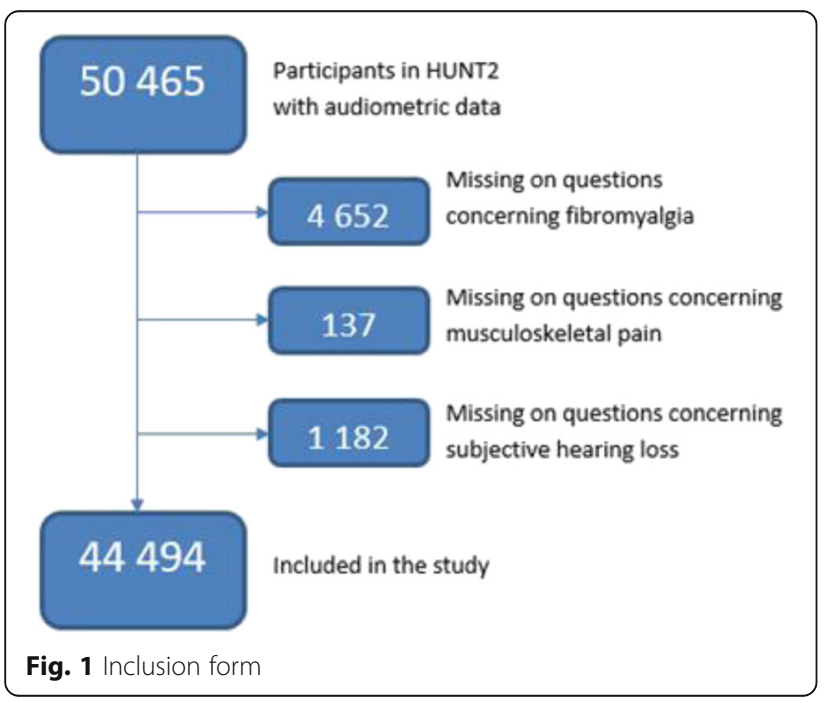

consecutive months? If so, where did you have these ailments?" Subsequently the participant could select between 10 different localizations [36]. Affirmative answers to one or more of the questions concerning musculoskeletal pain or stiffness, and not "yes" to the fibromyalgia question, were categorized as "having other musculoskeletal pain than fibromyalgia”.

\section{Widespread or localized pain}

Persons with muscular and/or skeletal problems in three or more localizations were categorized as having "widespread musculoskeletal pain" [37]. Those who had one to two localizations for musculoskeletal pain were categorized as having "localized musculoskeletal pain".

\section{Subjective hearing loss}

Subjective hearing loss (dependent variable) was assessed by the following questions and follow-up questions [32]: "Do you have any long-term illness, injury or suffering of physical or psychological nature that impairs your functioning in your daily life?". Then, if yes, "Impaired hearing?" and "How much would you say that your functions are impaired?" with grading options $0-3(0=$ not impaired, 1 = slightly impaired, 2 = mediocrely impaired and 3 =seriously impaired). Options $1-3$ were interpreted as subjective loss of hearing.

\section{Audiometry}

Audiometry measured the hearing threshold for air conduction. It was performed by trained personnel under good conditions [31, 38], and the method test-retest reliability is high [39]. The audiometry was performed automatically with earmuffs connected to a PC. In cases where the participant was not able to conduct the test automatically, it was performed manually. Hearing thresholds were measured by increasing sound levels until there was a response from the person, and then the sound level was lowered by $10 \mathrm{~dB}$ and then increased by $5 \mathrm{~dB}$, until a response was given once more [39]. The frequencies 500, 1000, 2000 and $4000 \mathrm{~Hz}$ for both ears form the basis of a mean hearing threshold in this study. Hearing loss is defined by the World Health Organization (WHO) as a mean hearing threshold of $26 \mathrm{~dB}$ or higher [40]. Mild hearing loss is mean hearing threshold of both ears between $26.0 \mathrm{~dB}$ and 40.9, moderate hearing loss is between 41.0 and $60.9 \mathrm{~dB}$, and severe hearing loss is defined by mean hearing threshold of $61.0 \mathrm{~dB}$ or above [41].

\section{Depression and anxiety symptoms}

Symptoms of depression and anxiety were assessed with the "Hospital Anxiety and Depression Scale" (HADS), a self-report form with seven questions for depressive symptoms (HADS-D) and seven questions for anxiety 
Table 1 Descriptive statistics

\begin{tabular}{|c|c|c|c|c|c|c|}
\hline & & Fibromyalgia & & Reference & Comparisor & ee $)^{a}$ \\
\hline & & & $\begin{array}{l}\text { paln without } \\
\text { fibromyalgia } \\
\text { (MS) }\end{array}$ & & FM vs Ref & MS vs Ref \\
\hline Total & $N(\%)$ & $1483(100)$ & $18808(100)$ & $24203(100)$ & & \\
\hline Women & $N(\%)$ & $1275(85.97)$ & 9948 (52.89) & $11860(49.00)$ & 0.000 & 0.000 \\
\hline Age & Mean (SD) & $52.43(12.02)$ & $51.64(15.56)$ & $45.99(16.77)$ & 0.000 & 0.000 \\
\hline Single & $N(\%)$ & $453(30.55)$ & $6340(33.71)$ & $10319(42.63)$ & 0.000 & 0.000 \\
\hline Education & & & & & 0.000 & 0.000 \\
\hline Primary school & $N(\%)$ & $716(48.28)$ & $7042(37.44)$ & $6647(27.46)$ & & \\
\hline High school & $N(\%)$ & $552(37.22)$ & 7936 (42.19) & 11091 (45.82) & & \\
\hline Higher & $N(\%)$ & $215(14.50)$ & $3830(20.36)$ & 6465 (26.71) & & \\
\hline Audiometry (MTH) & Mean (SD) & $16.82(13.19)$ & $17.65(14.80)$ & $14.29(13.86)$ & 0.000 & 0.000 \\
\hline HADS-A ${ }^{b}$ & Mean (SD) & $6.38(4.16)$ & $4.63(3.43)$ & $3.57(2.86)$ & 0.000 & 0.000 \\
\hline HADS-D ${ }^{b}$ & Mean (SD) & $5.07(3.65)$ & $3.83(3.15)$ & $2.81(2.67)$ & 0.000 & 0.000 \\
\hline
\end{tabular}

Reference $=$ Ref $=$ participants without fibromyalgia and musculoskeletal pain disorders

$\mathrm{MTH}=$ mean threshold of hearing based on pure tone audiometry at frequencies $0.5,1,2$ and $4 \mathrm{kHz}$ on both ears

HADS-A = self-reported questionnaire for symptoms of anxiety

HADS-D = self-reported questionnaire for symptoms of depression

${ }^{a}$ Descriptive comparison of categorical variables performed with chi-square and continuous variables with two-sided $t$-test

${ }^{\mathrm{b}}$ Missing data from several participants on this variable. Applicable for FM, MSD and Ref

symptoms (HADS-A) with a score range from $0-21$ points of each sub-scale. A score of $\geq 8$ on each subscale indicates clinically relevant symptoms consistent with depression (HADS-D) or anxiety (HADS-A) [42]. The HADS has been validated in Norway and found suitable for screening purposes [43].

\section{Demographic and socioeconomic status}

Demographic variables were gender and age (whole years) and assessment of socioeconomic status included level of education (highest completed - from primary school to university) [31].

\section{Statistical analysis}

Data was analyzed using SPSS version 22. Group differences of the participants were described by chi-square test for categorical variables and two-sided $t$-test for continuous variables.

Unadjusted and adjusted logistic regression analyses (the Enter method, i.e. including all relevant variables simultaneously) were used to assess the main outcome

Table 2 Local vs widespread musculoskeletal pain disorders without fibromyalgia

\begin{tabular}{|c|c|c|c|c|}
\hline & & Local musculoskeletal pain (LMS) & Widespread musculoskeletal pain (WMS) & Comparison LMS vs WMS (P-value $)^{a}$ \\
\hline Total & $N(\%)$ & $8749(100)$ & $10059(100)$ & \\
\hline Women & $N(\%)$ & $4158(47.52)$ & $5790(57.56)$ & 0.000 \\
\hline Age & Mean (SD) & $50.65(16.21)$ & $52.50(14.91)$ & 0.000 \\
\hline Single & $N(\%)$ & $3067(35.06)$ & $3273(32.54)$ & 0.000 \\
\hline Education & & & & 0.000 \\
\hline Primary school & $N(\%)$ & $2937(33.57)$ & $4105(40.81)$ & \\
\hline High school & $N(\%)$ & 3805 (43.49) & $4131(41.07)$ & \\
\hline Higher & $N(\%)$ & $2007(22.94)$ & $1823(18.12)$ & \\
\hline Audiometry (MTH) & Mean (SD) & $17.26(14.81)$ & $18.00(14.78)$ & 0.001 \\
\hline HADS-A ${ }^{b}$ & Mean (SD) & $4.13(3.11)$ & 5.07 (3.63) & 0.000 \\
\hline HADS-D ${ }^{b}$ & Mean (SD) & $3.48(2.97)$ & $4.14(3.27)$ & 0.000 \\
\hline
\end{tabular}

$\mathrm{MTH}=$ mean threshold of hearing based on pure tone audiometry at frequencies $0.5,1,2$ and $4 \mathrm{kHz}$ on both ears HADS-A = self-reported questionnaire for symptoms of anxiety

HADS-D = self-reported questionnaire for symptoms of depression

${ }^{a}$ Descriptive comparison of categorical variables performed with chi-square and continuous variables with two-sided $t$-test

${ }^{\mathrm{b}}$ Missing data from several participants on this variable. Applicable for FM, MSD and Ref 
Table 3 OR (95\% Cl) for subjective hearing loss by fibromyalgia, socioeconomic conditions, measured hearing loss, depression and anxiety in women and men ${ }^{a}$

\begin{tabular}{|c|c|c|c|c|c|}
\hline & \multicolumn{2}{|c|}{ Subjective hearing loss } & \multirow[t]{2}{*}{ Unadjusted } & \multirow{2}{*}{$\begin{array}{l}\text { Adjusted for age, } \\
\text { education and hearing } \\
\text { loss (model 1) }\end{array}$} & \multirow{2}{*}{$\begin{array}{l}\text { In addition adjusted for } \\
\text { anxiety and depression } \\
\text { (model 2) }\end{array}$} \\
\hline & Yes & No & & & \\
\hline & $N(\%)$ & $N(\%)$ & OR $(95 \% \mathrm{Cl})$ & OR $(95 \% \mathrm{Cl})$ & OR $(95 \% \mathrm{Cl})$ \\
\hline WOMEN (13 135) & $1085(8.26)$ & $12050(91.74)$ & & & \\
\hline \multicolumn{6}{|l|}{ Fibromyalgia } \\
\hline No & $805(6.79)$ & $11055(93.21)$ & 1.000 ref & 1.000 ref & 1.000 ref \\
\hline Yes & $280(21.96)$ & $995(78.04)$ & 3.865 (3.324-4.493) & $5.182(4.278-6.277)$ & $4.578(3.622-5.787)$ \\
\hline \multicolumn{6}{|l|}{ Age } \\
\hline $20-35$ & 89 (2.09) & $4162(97.91)$ & 1.000 ref & 1.000 ref & 1.000 ref \\
\hline $36-49$ & $135(3.36)$ & 3881 (96.64) & $1.627(1.240-2.133)$ & $1.069(0.801-1.426)$ & $0.974(0.713-1.329)$ \\
\hline $50-64$ & $279(10.24)$ & 2445 (89.76) & $5.336(4.182-6.809)$ & $2.072(1.565-2.743)$ & $1.952(1.437-2.651)$ \\
\hline $65+$ & $582(27.15)$ & $1562(72.85)$ & $17.424(13.837-21.942)$ & $2.354(1.747-3.172)$ & 2.071 (1.474-2.909) \\
\hline \multicolumn{6}{|l|}{ Education } \\
\hline Primary school & $659(15.45)$ & $3606(84.55)$ & 1.000 ref & 1.000 ref & 1.000 ref \\
\hline High school & $247(4.49)$ & $5255(95.51)$ & $0.257(0.221-0.299)$ & $0.807(0.665-0.980)$ & $0.736(0.588-0.921)$ \\
\hline Higher & $179(5.15)$ & 3189 (94.69) & $0.307(0.259-0.365)$ & $0.811(0.658-1.000)$ & $0.799(0.618-1.032)$ \\
\hline \multicolumn{6}{|l|}{ WHO hearing impairment } \\
\hline None $(<26 \mathrm{~dB})$ & $377(3.31)$ & 11007 (96.69) & 1.000 ref & 1.000 ref & 1.000 ref \\
\hline Mild (26-40 dB) & $325(28.33)$ & $822(71.67)$ & 11.544 (9.793-13.606) & 7.859 (6.404-9.644) & $8.082(6.340-10.302)$ \\
\hline Moderate (41-60 dB) & $291(59.75)$ & $196(40.25)$ & $43.348(35.201-53.380)$ & $31.533(24.444-40.678)$ & 35.904 (26.424-48.786) \\
\hline Severe (>60 dB) & $92(78.63)$ & $25(21.37)$ & $107.442(68.247-169.148)$ & 81.067 (50.190-130.939) & 90.053 (49.378-164.234) \\
\hline \multicolumn{6}{|l|}{ HADS-A $\geq 8^{b}$} \\
\hline No & $606(6.11)$ & 9312 (93.89) & 1.000 ref & & 1.000 ref \\
\hline Yes & $178(11.83)$ & $1327(88.17)$ & $2.061(1.727-2.460)$ & & $1.732(1.353-2.217)$ \\
\hline \multicolumn{6}{|l|}{ HADS-D $\geq 8^{b}$} \\
\hline No & $786(6.91)$ & $10590(93.09)$ & 1.000 ref & & $1.000 \mathrm{ref}$ \\
\hline Yes & $155(17.44)$ & $734(82.56)$ & $2.845(2.358-3.433)$ & & 1.131 (0.849-1.508) \\
\hline Nagelkerke $R^{2}$ & & & & 0.389 & 0.375 \\
\hline-2 Log likelihood & & & & 5056.265 & 3744.466 \\
\hline MEN (12 551) & $1404(11.19)$ & $11147(88.81)$ & & & \\
\hline \multicolumn{6}{|l|}{ Fibromyalgia } \\
\hline No & 1335 (10.82) & $11008(89.18)$ & 1.000 ref & 1.000 ref & 1.000 ref \\
\hline Yes & $69(33.17)$ & 139 (66.83) & 4.093 (3.050-5.493) & 4.368 (3.082-6.189) & $4.523(3.077-6.647)$ \\
\hline \multicolumn{6}{|l|}{ Age } \\
\hline $20-35$ & $150(3.93)$ & 3666 (96.07) & 1.000 ref & 1.000 ref & 1.000 ref \\
\hline $36-49$ & $173(4.54)$ & $3638(95.46)$ & 1.162 (0.930-1.453) & 1.007 (0.800-1.268) & $0.966(0.757-1.233)$ \\
\hline $50-64$ & $332(12.40)$ & $2346(87.60)$ & $3.459(2.833-4.223)$ & $1.692(1.351-2.119)$ & 1.609 (1.262-2.050) \\
\hline $65+$ & 749 (33.35) & $1497(66.65)$ & $12.228(10.159-14.718)$ & $2.116(1.661-2.695)$ & $1.837(1.404-2.403)$ \\
\hline \multicolumn{6}{|l|}{ Education } \\
\hline Primary school & $611(19.72)$ & $2487(80.28)$ & 1.000 ref & 1.000 ref & 1.000 ref \\
\hline High school & $505(8.22)$ & $5636(91.78)$ & $0.365(0.321-0.414)$ & $0.914(0.783-1.066)$ & $0.886(0.757-1.233)$ \\
\hline Higher & $288(8.70)$ & 3024 (91.30) & $0.388(0.334-0.450)$ & $0.824(0.691-0.981)$ & $0.765(0.622-0.940)$ \\
\hline
\end{tabular}


Table 3 OR (95\% Cl) for subjective hearing loss by fibromyalgia, socioeconomic conditions, measured hearing loss, depression and anxiety in women and men ${ }^{\text {a }}$ (Continued)

\begin{tabular}{|c|c|c|c|c|c|}
\hline \multicolumn{6}{|l|}{ WHO hearing impairment } \\
\hline None $(<26 \mathrm{~dB})$ & $438(4.36)$ & $9618(95.64)$ & 1.000 ref & 1.000 ref & 1.000 ref \\
\hline Mild (26-40 dB) & $439(28.16)$ & $1120(71.84)$ & 8.607 (7.437-9.961) & $5.625(4.713-6.715)$ & $6.157(5.054-7.500)$ \\
\hline Moderate (41-60 dB) & 410 (53.39) & $358(46.61)$ & $25.148(21.194-29.841)$ & $15.120(12.203-18.734)$ & $17.012(13.214-21.902)$ \\
\hline Severe (>60 dB) & $117(69.64)$ & $51(30.36)$ & $50.376(35.766-70.955)$ & $31.310(21.721-45.133)$ & 29.566 (19.085-45.802) \\
\hline \multicolumn{6}{|l|}{ HADS-A $\geq 8^{b}$} \\
\hline No & $949(9.20)$ & $9368(90.80)$ & 1.000 ref & & $1.000 \mathrm{ref}$ \\
\hline Yes & $128(13.43)$ & $825(86.57)$ & $1.532(1.257-1.867)$ & & $1.583(1.225-2.044)$ \\
\hline \multicolumn{6}{|l|}{ HADS-D $\geq 8^{\mathrm{b}}$} \\
\hline No & $1040(9.49)$ & 9915 (90.51) & 1.000 ref & & 1.000 ref \\
\hline Yes & $183(21.79)$ & $657(78.21)$ & $2.655(2.227-3.166)$ & & $1.429(1.118-1.826)$ \\
\hline Nagelkerke $\mathrm{R}^{2}$ & & & & 0.319 & 0.296 \\
\hline-2 Log likelihood & & & & 6593.252 & 5200.042 \\
\hline
\end{tabular}

HADS-A = self-reported questionnaire for symptoms of anxiety in which a score of $\geq 8$ is consistent with clinically relevant symptoms of anxiety HADS-D = self-reported questionnaire for symptoms of depression in which a score of $\geq 8$ is consistent with clinically relevant symptoms of depression ${ }^{\mathrm{a}} \mathrm{N}$ in this analysis ranges from 13135 to 11113 and 12551 to 10961 for respectively women and men

${ }^{\mathrm{b}}$ Missing data from several participants on this variable

of the study (to have subjective loss of hearing vs. no loss of hearing) of participants in HUNT2 with fibromyalgia versus the reference group. In addition, participants with other, widespread and localized, musculoskeletal pain were compared with the reference group. The reference group was participants without musculoskeletal pain. Men and women were analyzed separately. We adjusted for previously known confounding factors for subjective loss of hearing: measured loss of hearing (thresholds), socio-demographic factors (age and education), and psychological distress (clinical symptoms of depression and anxiety). Measured loss of hearing and age were not linearly associated with the outcome in any of the subgroups and was categorized. Two adjusted models were presented for both comparisons. Model 1 adjusted for age, education, and measured hearing thresholds. Model 2 was additionally adjusted for clinical symptoms of anxiety and depression.

Probability values less than 0.05 were considered statistically significant.

\section{Results}

\section{Descriptive account of participants}

The prevalence of fibromyalgia among participants who answered these questions in HUNT 2 and underwent audiometry testing was $3.3 \%(N=1483)$. The prevalence for other musculoskeletal pain was for local pain $19.7 \%(N=8$ 749), for widespread pain $22.6 \%(N=10059)$, and for local and widespread pain combined 42.3\% ( $N=18$ 808). Respondents who had fibromyalgia or other musculoskeletal pain were more often women, in a relationship, older, with lower level of education, higher scores of anxiety and depressive symptoms and higher average hearing thresholds than the reference group without fibromyalgia and musculoskeletal pain (Table 1).

Table 2 describes the two subgroups of persons with local and widespread musculoskeletal pain other than fibromyalgia. Persons with widespread pain were more commonly women, in a relationship, older, with lower level of education and higher scores of anxious and depressive symptoms, compared to persons with local musculoskeletal pain.

\section{The relationship between fibromyalgia and subjective hearing loss}

Table 3 shows that persons with fibromyalgia had increased probability of reporting subjective hearing loss, compared to persons in the reference group. The OR (95\% CI) for subjective hearing loss was 5.182 (4.2786.277) for women and 4.368 (3.082-6.189) for men with fibromyalgia, compared to women and men in the reference group after adjustment for age, education and measured hearing thresholds (WHO grade) (model 1). After additional adjustment for clinically relevant anxious and depressive symptoms (HADS-A $\geq 8$ and HADS-D $\geq 8$ ) (model 2), the OR (95\% CI) for subjective hearing loss was $4.578(3.622-5.787)$ for women and 4.523 (3.0776.647) for men with fibromyalgia.

\section{The relationship between other musculoskeletal pain than fibromyalgia and subjective hearing loss}

Table 4 shows that non-fibromyalgic persons who had local and widespread musculoskeletal pain had increased 
Table 4 OR (95\% Cl) for subjective hearing loss by musculoskeletal pain, socioeconomic conditions, measured hearing loss, depression and anxiety in women and men $^{\mathrm{a}}$

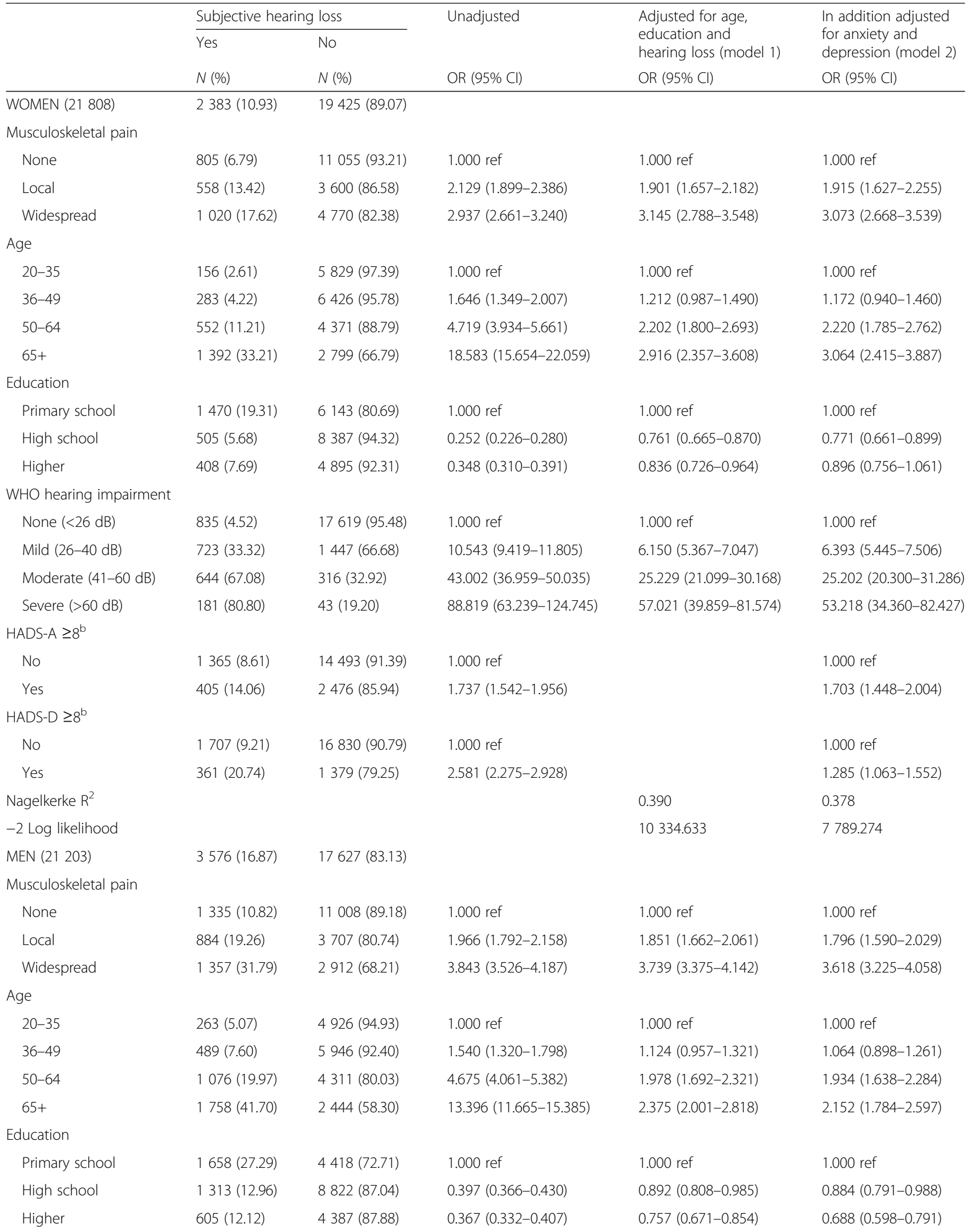


Table 4 OR (95\% Cl) for subjective hearing loss by musculoskeletal pain, socioeconomic conditions, measured hearing loss, depression and anxiety in women and men ${ }^{\text {a }}$ (Continued)

\begin{tabular}{|c|c|c|c|c|c|}
\hline \multicolumn{6}{|l|}{ WHO hearing impairment } \\
\hline None $(<26 \mathrm{~dB})$ & $1222(7.50)$ & $15080(92.50)$ & 1.000 ref & 1.000 ref & 1.000 ref \\
\hline Mild (26-40 dB) & 1135 (37.36) & $1903(62.64)$ & $7.360(6.701-8.084)$ & $4.775(4.270-5.341)$ & $4.842(4.361-5.600)$ \\
\hline Moderate (41-60 dB) & $962(62.63)$ & $574(37.37)$ & $20.682(18.368-23.288)$ & $12.982(11.221-15.020)$ & $13.428(11.428-16.060)$ \\
\hline Severe (>60 dB) & 257 (78.59) & $70(21.41)$ & 45.307 (34.566-59.386) & 31.241 (23.419-41.677) & $29.054(20.611-40.956)$ \\
\hline \multicolumn{6}{|l|}{ HADS-A $\geq 8^{b}$} \\
\hline No & $2386(14.25)$ & $14352(85.75)$ & 1.000 ref & & 1.000 ref \\
\hline Yes & $448(21.13)$ & $1672(78.87)$ & $1.612(1.440-1.804)$ & & $1.443(1.242-1.676)$ \\
\hline \multicolumn{6}{|l|}{ HADS-D $\geq 8^{b}$} \\
\hline No & 2577 (14.39) & $1533(85.61)$ & 1.000 ref & & 1.000 ref \\
\hline Yes & $585(30.02)$ & $1364(69.98)$ & $2.552(2.296-2.836)$ & & $1.555(1.342-1.801)$ \\
\hline Nagelkerke $\mathrm{R}^{2}$ & & & & 0.361 & 0.348 \\
\hline-2 Log likelihood & & & & 14108.014 & 11358.869 \\
\hline
\end{tabular}

HADS-A = self-reported questionnaire for symptoms of anxiety in which a score of $\geq 8$ is consistent with clinically relevant symptoms of anxiety HADS-D = self-reported questionnaire for symptoms of depression in which a score of $\geq 8$ is consistent with clinically relevant symptoms of depression ${ }^{\mathrm{a}} \mathrm{N}$ in this analysis ranges from 21808 to 18210 and 21203 to 18355 for respectively women and men

${ }^{\mathrm{b}}$ Missing data from several participants on this variable

probability of subjective hearing loss, compared to the reference group. The probability was stronger in the subgroup with widespread musculoskeletal pain, compared to the subgroup with localized pain. The OR $(95 \%$ CI) for subjective hearing loss was 1.901 (1.657-2.182) for women and $1.851(1.662-2.061)$ for men with local musculoskeletal pain, and $3.145(2.788-3.548)$ for women and 3.739 (3.375-4.142) for men with widespread musculoskeletal pain, compared to the reference group after adjustment for age, education and measured hearing thresholds (model 1). After additional adjustment for clinically relevant anxious and depressive symptoms (model 2), the OR $(95 \% \mathrm{CI})$ for subjective hearing loss was 1.915 (1.627-2.255) for women and 1.796 (1.590-2.029) for men with local musculoskeletal pain, and $3.073(2.668-3.539)$ for women and 3.618 (3.225-4.058) for men with widespread musculoskeletal pain.

\section{Discussion}

In this population-based study, we found that both persons who had been diagnosed with fibromyalgia and persons with other musculoskeletal pain had increased probability for subjective hearing, compared with a reference group without fibromyalgia or other musculoskeletal pain. The findings were adjusted for gender, age, education, measured hearing impairment (audiometry, WHO graded), clinical relevant symptoms indicating anxiety and/or depression. Non-fibromyalgia respondents with widespread musculoskeletal pain had significantly higher odds to report subjective hearing loss than persons with only localized pain.

\section{Main findings in light of theories about central nervous sensitization}

The previously mentioned theories about sustained arousal, CATS and allostatic overload all conceptualize how prolonged stress, probably in association with a genetic predisposition [44], lead to sensitization of the central nervous system, thereby enhancing the sensitivity to stimuli, by some researchers termed central sensitization syndrome (CSS) $[24,25]$. This indicates that both fibromyalgia and other musculoskeletal pain might to a certain extent be explained by altered central pain processing. Central mechanisms might explain both subjective alterations in the experience of auditory stimuli and cognitive dysfunction [17]. In future studies, it would be interesting to address auditory perception among patients with fibromyalgia and other chronic pain in a prospective and nuanced manner, encompassing both experiences of explicit hearing problems and hypersensitivity to sound.

\section{Comparisons with previous studies}

To our knowledge, our study is the first to report a relationship between subjective hearing loss and fibromyalgia, as well as for other musculoskeletal pain in a general population. The findings are in line with the previously mentioned clinical study by Wolfe et al. [28], which however did not adjust for audiometrically measured hearing loss. Hashimoto et al. [30] who revealed similar findings for conditions with three or more medical unexplained symptoms did not include fibromyalgia or other musculoskeletal pain disorders, nor did they 
adjust for depression and anxiety symptoms, but adjusted for measured hearing loss.

\section{Strengths and limitations}

This study has several strengths. Firstly, despite the large sample size (over 40000 participants) and the selfreport approach used in the study, all participants were assessed with audiometry in both ears with a validated procedure. Thus, it was possible to adjust the analysis of subjective hearing loss with objectively measured hearing thresholds. Furthermore, the large sample size gave power to run subgroup analyses and adjust for a number of conditions known to affect subjective health and hearing $[28,45,46]$.

Moreover, it is a strength that fibromyalgia and other musculoskeletal pain were studied separately in this study. This is because the new diagnostic criteria for fibromyalgia include more than just widespread musculoskeletal pain $[18,19]$. They also include cognitive dysfunction/problems, as stated in the introduction $[17,19]$.

Questions concerning musculoskeletal pain have been validated through several studies $[33,34]$ where they compared the answers on the questionnaires against the diagnoses cervical spondylosis, adhesive capsulitis, lateral epicondylitis, carpal tunnel syndrome and Raynaud's phenomenon [33]. Thus, the pain questions and pain map used in HUNT 2, i.e. the Nordic pain questionnaire (NPQ), appear relevant and valid [34].

The study also has some limitations. Firstly, the participants were not diagnosed by physicians in the study setting. The fibromyalgia diagnosis thus relied on the participant's response to whether a physician prior in time had said the person had fibromyalgia. Thus, we do not know if the persons responding "yes" to fibromyalgia was evaluated using the formal diagnostic criteria. The HUNT study was conducted in 1995-1997 when the 1990 diagnostic criteria for fibromyalgia were in force, thus 2010 criteria were not used. Furthermore, we cannot rule out the possibility that participants who reported widespread pain had undiagnosed fibromyalgia. In addition, we cannot exclude that wording in the questions concerning reported subjective hearing loss influenced the responses. Furthermore, since this is a retrospective cross-sectional study, conclusions concerning causality cannot be drawn from the results.

\section{Conclusions}

Our study showed increased probability for subjective hearing loss, both in persons with fibromyalgia and other musculoskeletal pain, especially widespread pain, after adjustment of audiometric measured hearing loss and sociodemographic and psychological variables. The finding supports the increasing recognition that medically unexplained pain conditions may pertain to a larger spectrum of symptoms, and that a common denominator for the different symptoms might be a more general dysregulation in perception of sensory stimuli.

\section{Abbreviations \\ ACR: American College of Rheumatology; CATS: Cognitive Activation Theory of Stress; CFS/ME: Chronic fatigue syndrome/myalgic encephalomyelitis; $\mathrm{Cl}$ : Confidence intervals; CSS: Central sensitization syndromes; dB: Decibel; FM: Fibromyalgia; HADS-A/D: Hospital Anxiety and Depression Scale - Anxiety/Depression; HUNT2 Q1: HUNT2 questionnaire 1; HUNT2: The Nord- Trøndelag Health Study part 2; Hz: Hertz; IC: Interstitial cystitis; LMS: Local musculoskeletal pain; MS: Musculoskeletal pain disorders; MTH: Mean threshold of hearing; NPQ: Nordic pain questionnaire; NTHLS: The Nord- Trøndelag Hearing Loss Study; NTNU: Norwegian University of Science and Technology; OR: Odds ratio; REK: Regional Ethics Committee for Medical Research Ethics; SSS: Symptom severity score; TMD: Temporomandibular disorder; WHO: World Health Organization; WMS: Widespread musculoskeletal pain; WPI: Widespread pain index}

\section{Acknowledgements}

The Nord-Trøndelag Health Study (The HUNT Study) is a collaboration between HUNT Research Centra, Faculty of Medicine, Norwegian University of Science and Technology (NTNU), Norwegian Institute of Public Health and Nord-Trøndelag County Council. The Nord-Trøndelag Hearing Loss Study, which is a part of HUNT, was funded by the National Institute on Deafness and Other Communication Disorders (NIDCD), NIH, research contract No N01-DC-62104. The authors also want to thank the NTHLS team for their diligence.

\section{Funding}

The present study was funded by Norwegian University of Science and Technology (NTNU).

\section{Availability of data and materials}

The data belongs to the Nord-Trøndelag Health Study and aggregated information is found at their website https://www.ntnu.no/hunt. Data used in the study were obtained by applying at HUNT's web application system.

\section{Authors' contributions}

ASH was responsible for the research idea. MS, HS, EAF, LG \& ASH developed the study. MS \& HS analyzed the majority of the data and drafted the manuscript. All authors participated in the analysis and interpretation of the study results and in editing the manuscript, and have read and approved the final manuscript.

\section{Authors' information}

MS and HS are medical students. EAF's previous research includes chronic widespread pain and fibromyalgia, fatigue and complex medically unexplained disorders, LG has worked with multimorbidity and allostatic load and ASH has long experience researching subjective and objective hearing problems.

\section{Competing interests}

The authors declare that they have no competing interests.

\section{Consent for publication}

Not applicable.

Ethics approval and consent to participate

The project was approved by the Regional Ethics Committee for Medical Research Ethics 2014/2258/REK midt). All participants in the Nord-Trøndelag Health Study and the Nord-Trøndelag Hearing Loss Study have given written informed consent to participate.

\section{Author details}

'Department of Public Health and General Practice, Faculty of Medicine, Norwegian University of Science and Technology (NTNU), Trondheim, Norway. ${ }^{2}$ St. Olav's University Hospital, Trondheim, Norway. ${ }^{3}$ Norwegian National Advisory Unit on Aging and Health, Vestfold Health Trust, Tønsberg, Norway. ${ }^{4}$ Harald Haarfagres gate 2, Trondheim NO-7041, Norway. 
Received: 30 June 2016 Accepted: 6 November 2016

Published online: 16 November 2016

\section{References}

1. Cosmacini $\mathrm{G}$. The long Art: the history of medicine from antiquity to the present. Rome: Oxford University Press; 1997.

2. Fors E. Hva er smerte? Oslo: Universitetsforlaget; 2012. p. 46

3. Inanici F, Yunus MB. History of fibromyalgia: past to present. Curr Pain Headache Rep. 2004:8(5):369-78.

4. Gowers W. Lumbago: its lessons and analogues. BMJ. 1904;1(2246):117-21.

5. Gowers WR. A lecture on lumbago: its lessons and analogues: delivered at the national hospital for the paralysed and epileptic. Br Med J. 1904;1(2246): 117-21.

6. Halliday JL. Psychological factors in rheumatism. Part II. Br Med J. 1937; 1(3970):264-9.

7. Hench PK. Nonarticular rheumatism, 22nd rheumatism review: review of the American and English literature for the years 1973 and 1974. Arthritis Rheum. 1976;19(suppl):1081-89.

8. Clauw DJ. Fibromyalgia: an overview. Am J Med. 2009;122(12 Suppl):S3-13.

9. Brown RJ. Introduction to the special issue on medically unexplained symptoms: background and future directions. Clin Psychol Rev. 2007;27(7): 769-80

10. Clauw DJ. Fibromyalgia: a clinical review. JAMA. 2014;311(15):1547-55.

11. Forseth $\mathrm{KO}, \mathrm{Gran} \mathrm{JT}$. The prevalence of fibromyalgia among women aged 20-49 years in Arendal, Norway. Scand J Rheumatol. 1992;21(2):74-8.

12. Wolfe F, et al. Fibromyalgia prevalence, somatic symptom reporting, and the dimensionality of polysymptomatic distress: results from a survey of the general population. Arthritis Care Res (Hoboken). 2013;65(5):777-85.

13. Wolfe F, et al. The American College of Rheumatology 1990 Criteria for the Classification of Fibromyalgia. Report of the Multicenter Criteria Committee. Arthritis Rheum. 1990;33(2):160-72.

14. Wessely S, Hotopf M. Is fibromyalgia a distinct clinical entity? Historical and epidemiological evidence. Baillieres Best Pract Res Clin Rheumatol. 1999; 13(3):427-36.

15. Aaron LA, Burke MM, Buchwald D. Overlapping conditions among patients with chronic fatigue syndrome, fibromyalgia, and temporomandibular disorder. Arch Intern Med. 2000;160(2):221-7.

16. Margret Olafia Tomasdottir, L.G., Johann A Sigurdsson, Halfdan Petursson, Anna Luise Kirkengen, Steinar Krokstad, Bruce McEwan, Irene Hetlevik, coand multimorbidity patterns in an unselected norwegian population: crosssectional analysis based on the hunt study and theoretical reflections concerning basic medical models. European journal for person centered healthcare, 2014

17. Landrø $\mathrm{Nl}$, et al. The extent of neurocognitive dysfunction in a multidisciplinary pain centre population. Is there a relation between reported and tested neuropsychological functioning? Pain. 2013;154(7):972-7.

18. Wolfe F, et al. The American College of Rheumatology preliminary diagnostic criteria for fibromyalgia and measurement of symptom severity. Arthritis Care Res (Hoboken). 2010;62(5):600-10.

19. Wolfe F, et al. Fibromyalgia criteria and severity scales for clinical and epidemiological studies: a modification of the ACR Preliminary Diagnostic Criteria for Fibromyalgia. J Rheumatol. 2011;38(6):1113-22.

20. Wessely S, Nimnuan C, Sharpe M. Functional somatic syndromes: one or many? Lancet. 1999;354(9182):936-9.

21. Woolf CJ. Central sensitization: implications for the diagnosis and treatment of pain. Pain. 2011;152(3 Suppl):S2-15.

22. Boomershine CS. Fibromyalgia: the prototypical central sensitivity syndrome Curr Rheumatol Rev. 2015;11(2):131-45.

23. Wyller VB, Eriksen HR, Malterud K. Can sustained arousal explain the Chronic Fatigue Syndrome? Behav Brain Funct. 2009;5:10.

24. Ursin H, Eriksen HR. Cognitive activation theory of stress (CATS). Neurosci Biobehav Rev. 2010;34(6):877-81.

25. McEwen BS, Kalia M. The role of corticosteroids and stress in chronic pain conditions. Metabolism. 2010;59 Suppl 1:S9-15.

26. Hansson P. Translational aspects of central sensitization induced by primary afferent activity: what it is and what it is not. Pain. 2014;155(10):1932-4.

27. Woolf $\mathrm{CJ}$. What to call the amplification of nociceptive signals in the central nervous system that contribute to widespread pain? Pain. 2014;155(10): 1911-2.
28. Wolfe F, Rasker JJ, Hauser W. Hearing loss in fibromyalgia? Somatic sensory and non-sensory symptoms in patients with fibromyalgia and other rheumatic disorders. Clin Exp Rheumatol. 2012;30(6 Suppl 74):88-93.

29. McDermid AJ, Rollman GB, McCain GA. Generalized hypervigilance in fibromyalgia: evidence of perceptual amplification. Pain. 1996;66(2-3):133-44.

30. Hashimoto $H$, Nomura $K$, Yano E. Psychosomatic status affects the relationship between subjective hearing difficulties and the results of audiometry. J Clin Epidemiol. 2004;57(4):381-5.

31. Holmen J, et al. The Nord-Trøndelag Health Study 1995-97 (HUNT 2): Objectives, contents, methods and participation. Norsk Epidemiologi. 2003;13(1):19-32.

32. HUNT. HUNT 2 Questionnaire 1. Available from [URL tested 2016 12. Nov]: http://www.ntnu.no/c/document_library/get_file?uuid=c6786f4d-6175-459ca80a-5d4268cc166e\&groupld=10304. Accessed 20 Nov 2015.

33. Palmer $\mathrm{K}$, et al. Repeatability and validity of an upper limb and neck discomfort questionnaire: the utility of the standardized Nordic questionnaire. Occup Med (Lond). 1999:49(3):171-5.

34. Descatha A, et al. Validity of Nordic-style questionnaires in the surveillance of upper-limb work-related musculoskeletal disorders. Scand J Work Environ Health. 2007;33(1):58-65.

35. Hagen $\mathrm{K}$, et al. Increasing prevalence of chronic musculoskeletal complaints. A large 11-year follow-up in the general population (HUNT 2 and 3). Pain Med. 2011:12(11):1657-66.

36. Kuorinka I, et al. Standardised Nordic questionnaires for the analysis of musculoskeletal symptoms. Appl Ergon. 1987;18(3):233-7.

37. Butler $\mathrm{S}$, et al. Chronic widespread pain-the need for a standard definition. Pain. 2016:157(3):541-3.

38. Standardization, G.I.O.f., ISO 8253-1. Aucoustics - Audiometric test methods. Part I: Basic pure-tone and bone conduction threshold audiometry. 1998. p. 1989.

39. Tambs K, et al. Hearing loss induced by noise, ear infections, and head injuries: results from the Nord-Trondelag Hearing Loss Study. Int J Audiol. 2003;42(2):89-105

40. World Health Organization, Deafness and hearing loss. 2014.

41. Organization, W.H., Global Burden of Disease 2004, W.H. Organization, Editor. 2004. p. 1-150. Available from [URL tested 2016 Nov 12.]: http:// www.who.int/healthinfo/global_burden_disease/GBD_report_2004update_ full.pdf?ua=1

42. Zigmond AS, Snaith RP. The hospital anxiety and depression scale. Acta Psychiatr Scand. 1983;67(6):361-70.

43. Bjelland I, et al. The validity of the hospital anxiety and depression scale. An updated literature review. J Psychosom Res. 2002;52(2):69-77.

44. Desmeules J, et al. Psychological distress in fibromyalgia patients: a role for catechol-O-methyl-transferase Val158met polymorphism. Health Psychol. 2012:31(2):242-9.

45. Tremblay $\mathrm{KL}$, et al. Self-reported hearing difficulties among adults with normal audiograms: the beaver Dam offspring study. Ear Hear. 2015;36(6): e290-9.

46. Galea S, Ahern J. Distribution of education and population health: an ecological analysis of New York City neighborhoods. Am J Public Health. 2005:95(12):2198-205.

\section{Submit your next manuscript to BioMed Central and we will help you at every step:}

- We accept pre-submission inquiries

- Our selector tool helps you to find the most relevant journal

- We provide round the clock customer support

- Convenient online submission

- Thorough peer review

- Inclusion in PubMed and all major indexing services

- Maximum visibility for your research

Submit your manuscript at www.biomedcentral.com/submit 